\title{
Biological control of Flavobacterium psychrophilum infection in ayu (Plecoglossus altivelis altivelis) using a bacteriophage PFpW-3
}

\author{
Ji Hyung Kim ${ }^{1,2}$, Se Chang Park ${ }^{1, *}$ \\ ${ }^{1}$ Laboratory of Aquatic Biomedicine, College of Veterinary Medicine and Research Institute for Veterinary Science, \\ Seoul National University, Seoul 08826, Korea \\ ${ }^{2}$ Infectious Disease Research Center, Korea Research Institute of Bioscience and Biotechnology, Daejeon 34141, Korea
}

(Received: October 27, 2017; Revised: February 6, 2018; Accepted: February 8, 2018)

\begin{abstract}
The efficacy of using a bacteriophage (phage) to control Flavobacterium psychrophilum (F. psychrophilum) infection of ayu (Plecoglossus altivelis altivelis) was evaluated in this study. Intramuscular challenge failed to induce sufficient infection levels; therefore, a newly designed net-scratch challenge method was also used to induce bacterial infection. Administration of phage PFpW-3 in F. psychrophilum-infected ayu showed notable protective effects, increased survival rates and mean times to death. Additionally, the fate of inoculated bacteria and phage in ayu were investigated. Our results suggest that the phage PFpW-3 could be considered an alternative biocontrol agent against $F$. psychrophilum infections in ayu culture.
\end{abstract}

Keywords: Flavobacterium psychrophilum, PFpW-3, ayu, bacteriophages

Flavobacterium psychrophilum (F. psychrophilum) is the causative agent of coldwater disease (CWD) and has been recognized recently as being responsible for appreciable economic losses related to aquaculture worldwide [2]. In Korea and Japan, wild and farmed ayu (Plecoglossus altivelis altivelis) have been shown to be severely affected by $F$. psychrophilum $[5,11]$. Infection of ayu occurs at different temperatures and exhibits different clinical signs than that of salmonid fishes [7]. To date, no commercial vaccine has been made available, and antibacterial chemotherapy tends to exert limited effects on CWD [14]. Moreover, with the emergence of antibiotic-resistant $F$. psychrophilum in fish cultures [10], alternative approaches to the treatment of CWD are urgently needed.

Recently, bacteriophages (phages) have been used as alternative therapeutic and prophylactic agents in aquaculture to control fish diseases and other infections in aqueous environments [8]. Several lytic phages infecting F. psychrophilum have been isolated and characterized [2, 3, 8, 14], and the application of phages as a protective measure against bacteria has been shown to reduce mortality in salmonids [2]. However, their effectiveness in preventing $F$. psychrophilum infection of ayu has not yet been evaluated. Therefore, the aim of this study was to evaluate the therapeutic potential of phages for F. psychrophilum infection of ayu using a novel experimental bacterial challenge method, and investigate the fate of the inoculated bacteria and phages.

F. psychrophilum strain N2-3 and the phage designated PFpW-3 [8] were used in this study. All bacterial culture and phage propagation procedures were carried out in accordance with a previous report [8], and a PCR assay [6] was used to confirm the presence of $F$. psychrophilum in fish of all experimental groups. For the animal experiments, four hundred healthy ayu (with an average weight of $48.9 \mathrm{~g}$ ) obtained from the Tokushima Prefectural Fish Farming Center (Japan) were acclimatized in $300 \mathrm{~L}$ fiberglass tanks with a flow-through water supply at $18 \pm 2^{\circ} \mathrm{C}$. The ayu were kept at $18^{\circ} \mathrm{C}$ for one week, during which they received commercial dry feed pellets. The food supply was discontinued $24 \mathrm{~h}$ prior to bacterial challenge. All of the procedures described in this study involving animals and their care were performed in accordance with the guidelines for animal experiments of Hiroshima University, Japan.

In order to evaluate the control efficacy of phage PFpW-3 against $F$. psychrophilum infection in ayu, one hundred and ten fish were divided into two groups of equal size and maintained in $300 \mathrm{~L}$ fiberglass tanks with a flow-through water supply at $18 \pm 2^{\circ} \mathrm{C}$. They were then challenged with a 0.05-mL suspension of live F. psychrophilum N2-3 in phosphatebuffered saline (PBS) by intramuscular (IM) injection $(6.2 \times$ $10^{5} \mathrm{CFU} /$ fish; CFU, colony-forming unit). Subsequently, one group (hereinafter referred to as "IM exp") was treated

*Corresponding author

Tel: $+82-2-880-1282$, Fax: $+82-2-880-1213$

E-mail: parksec@snu.ac.kr 
immediately with a phage suspension (at a final concentration of $3.4 \times 10^{6} \mathrm{PFU} / \mathrm{mL}$; PFU, plaque-forming unit) by immersion in a bath for $30 \mathrm{~min}$. The other group (hereinafter referred to as "IM cont") was treated with PBS only, as a control. A food supply was initiated on the following day at a rate of $0.5 \%$ of body weight, and the fish were kept for 14 days at $18^{\circ} \mathrm{C}$.

However, due to the insufficient levels of infection observed in experimental studies employing F. psychrophilum in various fish species [4, 13], a newly modified bacterial challenge technique causing artificial skin abrasions, named the net-scratch (NS) method, was adopted to enhance infectivity. In an aquarium, 80 ayu were left in a net gyrating at 100-120 gyrations/min for $5 \mathrm{~min}$ until the entire skin surface was scratched. The fish were then directly challenged with suspensions of live $F$. psychrophilum N2-3 (at a final concentration of $6.2 \times 10^{5} \mathrm{CFU} / \mathrm{mL}$ ) in PBS for $30 \mathrm{~min}$ by bath administration. After challenge, one group (hereinafter referred to as "NS exp") was treated immediately with a phage suspension (at a final concentration of $3.4 \times 10^{6} \mathrm{PFU} / \mathrm{mL}$ ) for $30 \mathrm{~min}$, also by bath administration. A second group (hereinafter referred to as "NS cont") was treated with PBS in place of phages, as a control. As above, food was supplied from the following day at a rate of $0.5 \%$ of body weight, and the fish were maintained at $18 \pm 2{ }^{\circ} \mathrm{C}$ for 14 days.

Separately, groups of ayu treated as above and kept under identical conditions were used to investigate the fate of the inoculated phages and bacteria. Kidneys (circa [ca.] $0.16 \mathrm{~g}$ each) from five randomly selected ayu per group were sampled at $0,3,24,72,120$, and $168 \mathrm{~h}$ after bacterial challenge and phage administration. The zero hour samples were collected before challenge to be used as a control for all of the treatment groups. All samples were thoroughly homogenized in PBS. One half of each homogenate was used to estimate the concentration of bacterial CFUs, and the other, that of phage PFUs. Enumeration of F. psychrophilum in kidney samples was achieved using a standard spread plate technique on cytophaga agar [15]. To ascertain phage concentrations, kidney homogenate was inoculated into $1 \mathrm{ml}$ cytophaga broth [1], which was then centrifuged for $10 \mathrm{~min}$ at $3,000 \times \mathrm{g}$. The supernatant $(250 \mu \mathrm{L})$ was subsequently subjected to a PFU assay based on the double-layer agar method, using $F$. psychrophilum N2-3 and cytophaga aga incubated for $48 \mathrm{~h}$ at $18^{\circ} \mathrm{C}$.

F. psychrophilum is a component of the fish microbiota of the skin, mucus, and connective tissue of fins, gills and opercula, and is readily transmitted horizontally between fish by waterborne and direct-contact routes [12]. However, effective establishment of $F$. psychrophilum infection by oral challenge has not been documented thus far [4, 12]. Therefore, in order to evaluate the efficacy of phages in protecting against $F$. psychrophilum infection, IM and NS methods were simultaneously utilized in this study.

The protective effects of bath administration of phages against $F$. psychrophilum infection are demonstrated in

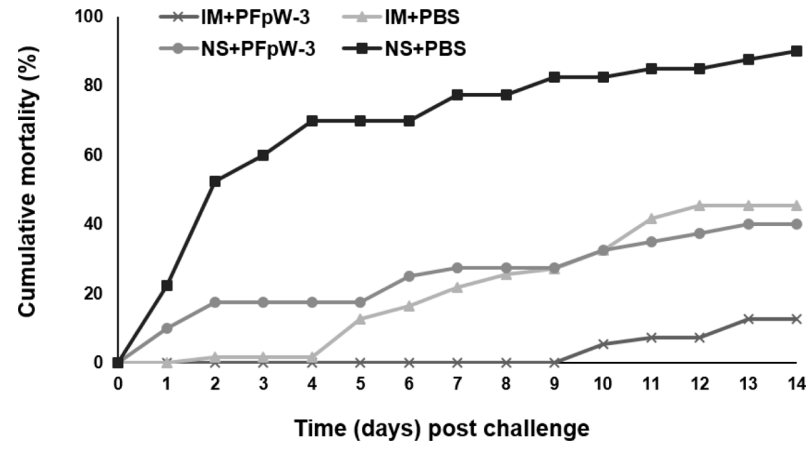

Fig. 1. The protective effects resulting from bath administration of phage PFpW-3 against Flavobacterium psychrophilum (F. psychrophilum) N2-3 challenge. IM+PFpW-3, IM-challenged and phage-administrated group; IM+PBS, IM-challenged group without phage administration; NS+PFpW-3, NS-challenged and phage-administrated group; NS+PBS, NS-challenged group without phage administration. IM, intramuscular injection; NS, net-scratch method.

Figure 1. The inoculated bacterium was identified in kidney samples from dead fish $(n=84)$ of all treatment groups, regardless of phage administration. Fish in the IM cont group began to die 2 days after bacterial challenge, and their cumulative mortality over the 2 weeks of the experiment was ca. $45.5 \%$ (with a mean time to death of 8.0 days). In contrast, those in the IM exp group began to die much later, with an average cumulative mortality of ca. $12.7 \%$ (and a mean time to death of 11.4 days). The mortality of phageadministered fish was therefore lower than that of those given PBS. However, IM administration in this study failed to induce high mortality and sufficient infectivity, necessitating a different approach to systemic bacterial challenge. It has previously been reported that abrasion of the skin and mucus enhances pathogen invasion of fish (including ayu) challenged by bath and cohabitation methods $[12,13]$. Therefore, the newly designed NS infection technique was employed. Using this procedure, we observed increased infectivity and mortality compared to IM challenge. Fish in the NS cont group began to die 1 day after bacterial exposure, and cumulative mortality after 2 weeks was $90.0 \%$ (with a mean time to death of 3.8 days). In contrast, although NS exp fish also started dying at day 1 , the average cumulative mortality in this group was $40.0 \%$ (with a mean time to death of 5.7 days). Interestingly, bacterial CFU/g values increased more rapidly in the NS cont group than the IM cont group, supporting the effectiveness of the NS method over IM challenge. Moreover, mortality in the phage-administered groups (IM exp and NS exp) was lower than that in the control groups (IM cont and NS cont), and the protective effects of phage treatment were more evident using the NS protocol than IM injection. These results suggest that phage PFpW-3 can be considered as an alternative biological control agent for $F$. psychrophilum infections in Korean and Japanese ayu cultures.

Additionally, the fate of inoculated bacteria and phage in 
Table 1. Fates of challenged F. psychrophilum N2-3 and administrated phage PFpW-3 in ayu

\begin{tabular}{|c|c|c|c|c|c|c|c|c|c|}
\hline \multirow{2}{*}{$\begin{array}{l}\text { Time after } \\
\text { treatment }(\mathrm{h})\end{array}$} & \multirow{2}{*}{$\begin{array}{l}\text { Fish sample } \\
\text { nunmber }\end{array}$} & \multicolumn{2}{|c|}{$\begin{array}{l}\text { F. psychrophilum }(\mathrm{CFU} / \mathrm{g}) \\
\text { in ayu kidney }\end{array}$} & \multicolumn{2}{|c|}{$\begin{array}{l}\text { PFpW-3 (PFU/g) } \\
\text { in ayu kidney }\end{array}$} & \multicolumn{2}{|c|}{$\begin{array}{c}\text { F. psychrophilum }(\mathrm{CFU} / \mathrm{g}) \\
\text { in ayu kidney }\end{array}$} & \multicolumn{2}{|c|}{$\begin{array}{l}\text { PFpW-3 (PFU/g) } \\
\text { in ayu kidney }\end{array}$} \\
\hline & & IM exp & IM cont & IM exp & IM cont & NS exp & NS cont & NS exp & NS cont \\
\hline \multirow[t]{5}{*}{$0^{*}$} & $0-1$ & $--^{\dagger}$ & $-\dagger$ & $--^{\dagger}$ & $--^{\dagger}$ & $-\dagger$ & $--^{\dagger}$ & $-{ }^{\dagger}$ & $-\dot{+}$ \\
\hline & $0-2$ & - & - & - & - & - & - & - & - \\
\hline & $0-3$ & - & - & - & - & - & - & - & - \\
\hline & $0-4$ & - & - & - & - & - & - & - & - \\
\hline & $0-5$ & - & - & - & - & - & - & - & - \\
\hline \multirow[t]{5}{*}{3} & $3-1$ & - & - & $3.8 \times 10^{2}$ & - & - & $3.5 \times 10^{2}$ & $2.0 \times 10^{2}$ & - \\
\hline & $3-2$ & - & - & $1.4 \times 10^{3}$ & - & $5.0 \times 10^{1}$ & - & $7.0 \times 10^{2}$ & - \\
\hline & $3-3$ & $1.0 \times 10^{2}$ & $1.8 \times 10^{2}$ & $2.3 \times 10^{2}$ & - & - & - & $2.3 \times 10^{2}$ & - \\
\hline & $3-4$ & $5.0 \times 10^{1}$ & - & $5.0 \times 10^{1}$ & - & - & - & $4.8 \times 10^{2}$ & - \\
\hline & $3-5$ & - & - & $1.5 \times 10^{2}$ & - & - & - & $3.5 \times 10^{2}$ & - \\
\hline \multirow[t]{5}{*}{24} & $24-1$ & - & $5.0 \times 10^{1}$ & $6.0 \times 10^{2}$ & - & - & $2.8 \times 10^{2}$ & $2.3 \times 10^{4}$ & - \\
\hline & $24-2$ & - & - & $7.3 \times 10^{3}$ & - & - & $3.5 \times 10^{2}$ & $2.4 \times 10^{5}$ & - \\
\hline & $24-3$ & $1.5 \times 10^{2}$ & - & $4.0 \times 10^{2}$ & - & - & $6.3 \times 10^{2}$ & $1.4 \times 10^{5}$ & - \\
\hline & $24-4$ & $2.5 \times 10^{1}$ & - & - & - & - & $5.0 \times 10^{1}$ & $4.5 \times 10^{5}$ & - \\
\hline & $24-5$ & $6.8 \times 10^{2}$ & $5.0 \times 10^{1}$ & $5.0 \times 10^{1}$ & - & $7.5 \times 10^{1}$ & - & $2.8 \times 10^{5}$ & - \\
\hline \multirow[t]{5}{*}{72} & $72-1$ & - & - & - & - & $1.5 \times 10^{2}$ & $3.5 \times 10^{2}$ & $9.7 \times 10^{3}$ & - \\
\hline & $72-2$ & - & $2.5 \times 10^{2}$ & $7.8 \times 10^{4}$ & - & - & - & $7.2 \times 10^{4}$ & - \\
\hline & $72-3$ & - & $1.8 \times 10^{4}$ & - & - & - & - & $2.3 \times 10^{3}$ & - \\
\hline & $72-4$ & - & $7.5 \times 10^{1}$ & $1.9 \times 10^{4}$ & - & - & $4.5 \times 10^{2}$ & $3.0 \times 10^{3}$ & - \\
\hline & $72-5$ & - & - & - & - & $5.0 \times 10^{1}$ & - & $5.4 \times 10^{4}$ & - \\
\hline \multirow[t]{5}{*}{120} & $120-1$ & - & - & - & - & - & - & - & - \\
\hline & $120-2$ & - & - & - & - & $3.8 \times 10^{2}$ & - & - & - \\
\hline & $120-3$ & - & - & - & - & - & - & - & - \\
\hline & $120-4$ & - & $5.0 \times 10^{1}$ & - & - & $5.7 \times 10^{3}$ & - & - & - \\
\hline & $120-5$ & - & - & - & - & - & - & - & - \\
\hline \multirow[t]{5}{*}{168} & $168-1$ & - & - & - & - & - & - & - & - \\
\hline & $168-2$ & - & - & - & - & - & - & - & - \\
\hline & $168-3$ & - & - & - & - & - & - & - & - \\
\hline & $168-4$ & - & - & - & - & - & - & - & - \\
\hline & $168-5$ & - & - & - & - & - & - & - & - \\
\hline
\end{tabular}

${ }^{*}$ Zero hour samples were collected before bacterial challenges and phage administrations. ${ }^{\dagger}$ The quantities of phage and F. psychrophilum in kidney samples were lower than $2.5 \times 10^{1} \mathrm{PFU} / \mathrm{g}$ and $2.5 \times 10^{1} \mathrm{CFU} / \mathrm{g}$, respectively. PFU, plaque-forming unit; CFU, colony-forming unit.

ayu were also investigated. F. psychrophilum was detected in samples collected from 3 to $120 \mathrm{~h}$ after challenge, and its concentration finally decreasing below the detection limit $\left(2.5 \times 10^{1} \mathrm{CFU} / \mathrm{g}\right)$ by $168 \mathrm{~h}$ in all groups (Table 1$)$. The kidney samples revealed notable differences in bacterial fate between the IM and NS groups (Fig. 2A). Regarding IM administration, F. psychrophilum CFU/g values in fish exposed to phages were higher than those of the controls until $24 \mathrm{~h}$ post-challenge. The protective effects of phage treatment were then observed 72 and $120 \mathrm{~h}$ after challenge in the IM exp group. However, an antibacterial impact was evident from 3 to $120 \mathrm{~h}$ in the NS exp group, samples from which exhibited low CFU/g values compared to those of the NS cont group. These findings further demonstrate that phage PFpW-3 is able to inhibit bacterial growth in ayu and that it could be used prophylactically to prevent horizontal transmission of F. psychrophilum.

PFpW-3 was detected from $3 \mathrm{~h}$ post-administration in samples from both groups treated with this phage (Fig. 2B and Table 1), indicating that it permeated tissues and reached the kidneys of fish in each group equally, regardless of skin damage. Thus, as both groups were treated in the same manner (bath administration), phages were unlikely to have entered through the skin. Moreover, the PFU/g values of the phageadministered groups increased 24 and $72 \mathrm{~h}$ post-treatment, suggesting that phages had successfully propagated and lysed 


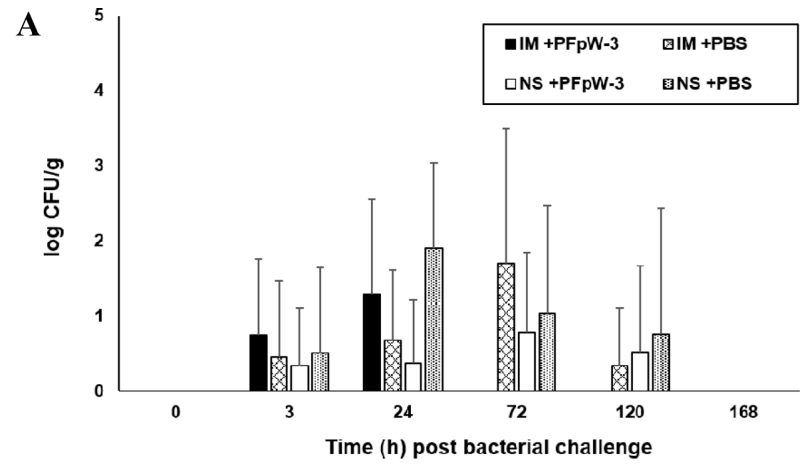

B

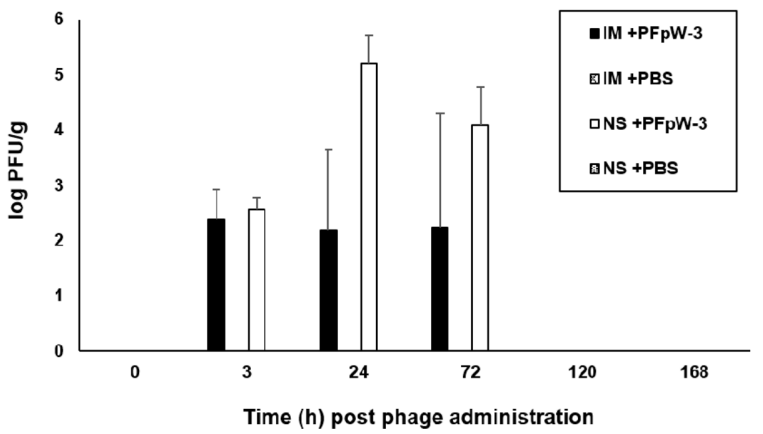

Fig. 2. Fates of phage PFpW-3 and F. psychrophilum N2-3 in ayu kidney samples from IM-challenged and phage-administrated group (IM+PFpW-3), IM-challenged group without phage administration (IM+PBS), NS-challenged and phageadministrated group (NS+PFpW-3) and NS-challenged group without phage administration (NS+PBS), respectively. Bars indicate SD. *No phage (PFpW-3) and F. psychrophilum (N2-3) was detected in the group (Detection limit: $<2.5 \times 10^{1} \mathrm{PFU} / \mathrm{g}$ and $<2.5 \times 10^{1} \mathrm{CFU} / \mathrm{g}$ ). The zero hour samples were collected before treatment and used as control of phage-administrated group and bacterial-challenged group.

F. psychrophilum in ayu kidneys. However, the extent and timing of such increases differed between the two groups. Phage PFU/g values in the NS exp group had increased by $24 \mathrm{~h}$ post-administration, whereas those in the IM exp group were similar at 3 and $24 \mathrm{~h}$, eventually increasing at $72 \mathrm{~h}$. Based on these results, we speculate that the early increase in phage levels inhibited fatal bacterial growth, resulting in retained mean time to death and reduced mortality in the NS exp group compared to the IM exp group.

Interestingly, fluctuations in the concentration of phages between 72 and $120 \mathrm{~h}$ post-administration did not correspond to changes in bacterial CFU/g values. Furthermore, despite the presence of $F$. psychrophilum in ayu kidneys at $120 \mathrm{~h}$, phage levels were dramatically decreased, to below the detection limit $\left(2.5 \times 10^{1} \mathrm{PFU} / \mathrm{g}\right)$. Similar results were obtained in a previous study involving Aeromonas salmonicida [9], in which phages were found to be undetectable in the kidneys of rainbow trout (Oncorhynchus mykiss) $200 \mathrm{~h}$ after inoculation. Thus, it may be hypothesized that the phages, having permeated the fish and propagated in their bacterial host in the kidney, maintain their infectivity for a limited time before finally decreasing in number due to an unknown response in the ayu. According to previous phage stability tests [8], no other environmental conditions can cause such a rapid decrease in phage PFU levels. Thus, the sudden reduction in phage concentrations in the kidney observed in the present work reveals that ayu may also develop humoral immunity to phages administered during biocontrol efforts.

Recent investigations concerning the application of phages in aquaculture have mainly concentrated on their interactions with host bacteria, whereas the immune responses of fish to such phages have not been well studied. Therefore, the relationship between phages and recipient fish should also be considered as an important factor affecting their successful use in aquaculture biocontrol.

\section{Acknowledgments}

The authors greatly appreciate the valuable advices and technical supports from Dr. Nakai Toshihiro and the staffs of Tokushima Prefectural Fisheries Experiment Stations. This study was financially supported by the Basic Science Research Program through the National Research Foundation of Korea (NRF), funded by the Ministry of Education (2014R1A2A1A11050093), Republic of Korea.

\section{References}

1. Anacker RL, Ordal EJ. Study of a bacteriophage infecting the myxobacterium Chondrococcus columnaris. J Bacteriol 1955, 70, 738-741.

2. Castillo D, Higuera G, Villa M, Middelboe M, Dalsgaard I, Madsen L, Espejo RT. Diversity of Flavobacterium psychrophilum and the potential use of its phages for protection against bacterial cold water disease in salmonids. $\mathrm{J}$ Fish Dis 2012, 35, 193-201.

3. Christiansen RH, Dalsgaard I, Middelboe M, Lauritsen AH, Madsen L. Detection and quantification of Flavobacterium psychrophilum-specific bacteriophages in vivo in rainbow trout upon oral administration: implications for disease control in aquaculture. Appl Environ Microbiol 2014, 80, 7683-7693.

4. Decostere A, Lammens M, Haesebrouck F. Difficulties in experimental infection studies with Flavobacterium psychrophilum in rainbow trout (Oncorhynchus mykiss) using immersion, oral and anal challenges. Res Vet Sci 2000, 69, 165-169.

5. Iida Y, Mizokami A. Outbreaks of coldwater disease in wild ayu and pale chub. Fish Pathol 1996, 31, 157-164.

6. Izumi S, Wakabayashi H. Sequencing of $\operatorname{gyr} B$ and their application in the identification of Flavobacterium psychrophilum by PCR. Fish Pathol 2000, 35, 93-94.

7. Kato G, Suzuki K, Sakai T, Kawakami M, Takano T, Matsuyama T, Nakayasu C. The role of a specific antibody against Flavobacterium psychrophilum infection in ayu sweetfish, Plecoglossus altivelis altivelis (Temminck \& Schlegel, 1846). J Fish Dis 2015, 38, 107-112.

8. Kim JH, Gomez DK, Nakai T, Park SC. Isolation and identification of bacteriophages infecting ayu Plecoglossus altivelis altivelis specific Flavobacterium psychrophilum. Vet Microbiol 2010, 140, 109-115. 
9. Kim JH, Choresca CH, Shin SP, Han JE, Jun JW, Park SC. Biological control of Aeromonas salmonicida subsp. salmonicida infection in rainbow trout (Oncorhynchus mykiss) using Aeromonas phage PAS-1. Transbound Emerg Dis 2015, 62, 81-86.

10. LaFrentz BR, LaPatra SE, Call DR, Cain KD. Isolation of rifampicin resistant Flavobacterium psychrophilum strains and their potential as live attenuated vaccine candidates. Vaccine 2008, 26, 5582-5589.

11. Lee KB, Heo GJ. First isolation and identification of Cytophaga psychrophila from cultured ayu in Korea. Fish Pathol 1998, 33, 37-38.

12. Madetoja J, Nyman P, Wiklund T. Flavobacterium psychrophilum, invasion into and shedding by rainbow trout Oncorhynchus mykiss. Dis Aquat Organ 2000, 43, 27-38.

13. Miwa S, Nakayasu C. Pathogenesis of experimentally induced bacterial cold water disease in ayu Plecoglossus altivelis. Dis Aquat Organ 2005, 67, 93-104.

14. Stenholm AR, Dalsgaard I, Middelboe M. Isolation and characterization of bacteriophages infecting the fish pathogen Flavobacterium psychrophilum. Appl Environ Microbiol 2008, 74, 4070-4078.

15. Wakabayashi H, Egusa S. Characteristics of myxobacteria associated with some freshwater fish diseases in Japan. Bull Jpn Soc Sci Fish 1974, 40, 751-757. 